\title{
CARACTERIZAÇÃO MICROESTRUTURAL E ESTUDO CINÉTICO DE TRANSFORMAÇÃO DE FASES EM DOIS AÇOS STANDARD E PREMIUM DE APLICAÇÃO FERRỎVIÁRIA*
}

\author{
Geraldo Lúcio de Faria ${ }^{1}$ \\ Leonardo Barbosa Godefroid² \\ Luiz Cláudio Cândido ${ }^{3}$ \\ Rodrigo Rangel Porcaro 4
}

\section{Resumo}

O sucesso do transporte ferroviário depende, entre outras coisas, da integridade física dos componentes metálicos empregados na via permanente. Um dos mais importantes é o trilho, pois falhas catastróficas deste componente podem gerar graves acidentes. No intuito de desenvolver aços com bom desempenho para esta aplicação, estudos têm sido desenvolvidos para se entender os efeitos de composição química e histórico de processamento termomecânico sobre a microestrutura e propriedades mecânicas dos aços. Neste contexto, este trabalho caracterizou microestruturalmente dois aços de aplicação ferroviária, sendo um Standard e um Premium. Amostras representativas destes aços foram submetidas a ensaios dilatométricos e a cinética de transformação de fases austenita-perlita foi investigada. Por meio dos resultados obtidos, foi possível concluir que o aço Premium estudado possui microestrutura mais refinada e que este efeito é devido, principalmente, à menor concentração de $\mathrm{Mn}$ em sua composição química. O menor teor de Mn facilita a nucleação de cementita eutetóide, possibilitando a formação de perlita em tempos mais curtos e temperaturas mais baixas do que no aço Standard. Isto possibilita que o aço Premium, em seu processo de fabricação, possa ser resfriado a taxas mais elevadas do que o Standard sem formação de martensita, justificando sua estrutura mais refinada.

Palavras-chave: Trilhos; Aços Eutetóides, Cinética de transformação de fases.

\section{MICROSTRUCTURAL CHARACTERIZATION AND KINETIC STUDY ABOUT PHASE TRANSFORMATIONS IN STANDARD AND PREMIUM RAIL STEELS}

\section{Abstract}

The success of railroad transport depends, between other things, of the metallic component physical integrity. One of the most important is the rail, because its suddenly fail may cause serious accidents. Aiming to develop high performance steels for this application, many research works have been developed to better understand the effects of chemical composition and thermomechanical processing on steel microstructure and mechanical properties. In this context, this work characterized microstructurally two rail steels, one of them Standard and the other Premium. Representative samples were submitted to dilatometric tests and the kinetic of phase transformation austenite-pearlite were studied. In behalf of obtained results, it was possible to conclude that Premium steel has the most refined structure and this is mainly due to its lowest Mn content. The lowest $\mathrm{Mn}$ content facilitates the euctetoid cementite nucleation, allowing the faster pearlite formation in lower temperatures than the verified for Standar steel. These facts allow Premium steel, to be, in its manufacturing process, cooled with higher cooling rates than Standard steel, justifying its more refined structure.

Keywords: Rails; Eutectoid steels; Kinetic of phase transformations.

Físico, Dr., Professor, Departamento de Engenharia Metalúrgica e de Materiais (DEMET),

Universidade Federal de Ouro Preto (UFOP), Ouro Preto, Minas Gerais, Brasil.

Engenheiro Metalúrgico, Dr., Professor, DEMET, UFOP, Ouro Preto, Minas Gerais, Brasil.

Engenheiro Metalúrgico, Dr., Professor, DEMET, UFOP, Ouro Preto, Minas Gerais, Brasil.

Engenheiro Metalúrgico, MSc., Professor, DEMET, UFOP, Ouro Preto, Minas Gerais, Brasil. 


\section{INTRODUÇÃO}

Uma das maneiras para atender à crescente demanda por transporte de grandes volumes de carga por longas distância é a utilização do transporte ferroviário. A necessidade de aumentar o tráfego de composições, a velocidade e a carga por eixo impulsiona o surgimento de tecnologias específicas para a construção de ferrovias. Um exemplo é o caso da utilização de trilhos longos soldados (TLS) [1].

Para que o transporte ferroviário seja eficiente, é importante, entre outras coisas, garantir a integridade das ferrovias. Falhas catastróficas em trilhos, durante a passagem de composições, podem levar a descarrilhamentos, culminando em acidentes com perdas de vidas humanas e de bens materiais [2].

Avanços têm sido feitos na prevenção de falhas em trilhos por meio do aprofundamento do conhecimento dos mecanismos de fadiga, fenômeno este responsável pela causa da maioria das fraturas neste componente. Para aumentar a vida útil das ferrovias, atualmente são utilizados na fabricação de trilhos ferroviários, aços modernos com microestruturas complexas e baixa concentração de impurezas. Além disso, tratamentos térmicos têm sido empregados após a laminação a quente para conferir a eles elevada resistência mecânica e ao desgaste [3-5].

Segundo a AREMA (2003), os aços para trilhos podem ser classificados em duas classes, os Standard e os Premium. Os parâmetros adotados como critério de classificação são a composição química e as propriedades mecânicas finais do trilho, basicamente de dureza, limites de escoamento e de resistência [3-5].

Segundo Olivares et al. (2011) e outros autores, os aços Premium têm sido fabricado, nos últimos anos, com concentração em peso de C entre $0,7 \%$ e $0,9 \%$. O teor de $\mathrm{Mn}$ pode variar de $0,8 \%$ a $1,3 \%$ e os teores de fósforo e enxofre são controlados, respectivamente, entre $0,005-0,007 \%$ e abaixo de $0,003 \%$. Segundo estes autores, o fósforo e o enxofre são controlados para evitar problemas relacionados à fragilização dos aços e a presença excessiva de inclusões de sulfeto de manganês. Adições de outros elementos como $\mathrm{Si}$, $\mathrm{Cr}$, Mo, $\mathrm{Nb}$ e $\mathrm{V}$ também podem ser desejáveis para que características como tamanho de grão austenítico prévio, espaçamento interlamelar, inibição do crescimento do filme de cementita na perlita, entre outras, sejam controladas [6-8].

O Si aumenta a atividade do carbono tanto na austenita quanto na ferrita, dificultando a formação de cementita. O manganês, elemento $\gamma$-gêneo, expande 0 campo de austenita estável, deslocando a composição eutetóide para a esquerda e a temperatura eutetóide para baixo, reduzindo a formação de ferrita proeutetóide. A adição de $\mathrm{Cr}$, Mo e $\mathrm{V}$, bons formadores de carbonetos, restringem o crescimento dos filmes de cementita na perlita e, quando austenitizado, controlam o crescimento de grão austenítico do aço [7-11].

Alguns fabricantes de aços para trilhos buscam rotas alternativas para se atingir a classe Premium sem adição significativa dos elementos pré-citados, mas acelerando o resfriamento do trilho após laminação, de forma a obter uma microestrutura perlítica muito fina, sem formação de martensita. Para que estas tentativas tenham sucesso, é necessário que se tenha conhecimento preciso sobre a cinética de transformação de fases nestes aços em condições de resfriamento contínuo.

Para o entendimento tecnológico de rotas alternativas de fabricação de trilhos ferroviários, por exemplo por meio de modificações no perfil térmico após laminação, assim como para propor possíveis soluções para minimizar o efeito maléfico das zonas termicamente afetadas em juntas soldadas de trilhos (TLS), estudos têm sido desenvolvidos por diversos pesquisadores [6-12]. 
Neste contexto, este trabalho apresenta um estudo de caracterização microestrutural do estado de entrega e da cinética de transformação de fases em dois aços de aplicação ferroviários atualmente empregados na malha ferroviária Brasileira, sendo um Standard (S) e o outro Premium (P). Este estudo tem grande relevância, visto que o conhecimento científico Brasileiro a respeito destes trilhos, que há muitas décadas não são fabricados no Brasil, ainda é restrito.

\section{MATERIAIS E MÉTODOS}

\subsection{Materiais}

Os materiais utilizados neste trabalho foram dois aços obtidos a partir do centro do boleto de trilhos ferroviários. Os aços foram denominados $\mathrm{S}$ e $\mathrm{P}$, sendo o primeiro considerado Standard e o segundo Premium, segundo a norma AREMA (2013). A composição química dos aços foi obtida por espectrometria de emissão óptica e é apresentada na Tabela 1.

Tabela 1. Composição química dos aços estudados (\% em peso).

\begin{tabular}{lccccccccc}
\hline Aço & $\mathrm{C}$ & $\mathrm{Mn}$ & $\mathrm{Si}$ & $\mathrm{P}$ & $\mathrm{S}$ & $\mathrm{Cr}$ & $\mathrm{Ni}$ & $\mathrm{Mo}$ & $\mathrm{V}$ \\
\hline $\mathrm{S}$ & 0,72 & 1,24 & 0,54 & 0,015 & 0,004 & 0,22 & 0,026 & 0,017 & 0,003 \\
\hline $\mathrm{P}$ & 0,79 & 0,88 & 0,30 & 0,017 & 0,004 & 0,21 & 0,023 & 0,017 & 0,002 \\
\hline
\end{tabular}

\subsection{Procedimentos Experimentais}

\subsubsection{Ensaios de Dilatometria}

Corpos de prova para ensaios de dilatometria foram preparados na oficina mecânica do DEMET/UFOP. Os corpos de prova possuem seção cilíndrica com $3 \mathrm{~mm}$ de diâmetro e $10 \mathrm{~mm}$ de comprimento, conforme ilustrado na Figura 1, na qual pode-se observar também um termopar do tipo $\mathrm{K}$ soldado na superfície de um corpo de prova.

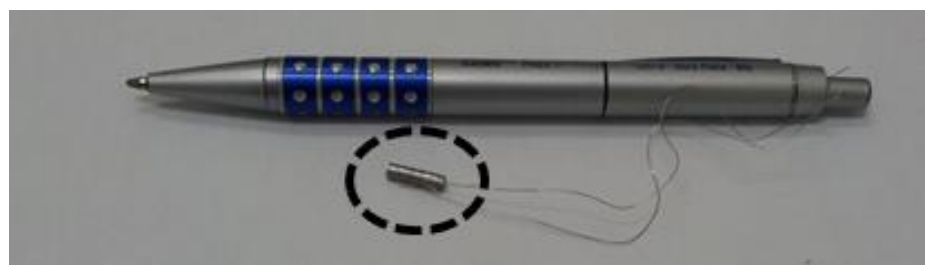

Figura 1. Corpo de prova de dilatometria (tracejado) usinado a partir de aço de trilho com termopar do tipo K soldado na superfície.

Os ensaios de dilatometria foram realizados em um dilatômetro R.I.T.A. L78 do Laboratório de Tratamentos Térmicos e Microscopia Óptica (LTM) do DEMET/UFOP. A temperatura de austenitização definida foi $900^{\circ} \mathrm{C}$ para os dois aços. Os ciclos térmicos aplicados são apresentados na Figura 2, na qual pode-se perceber a taxa de aquecimento $(1 \mathrm{~K} / \mathrm{s})$, o tempo de encharque (60s) e as diferentes taxas de resfriamento contínuo aplicadas para os dois aços.

A partir de uma análise prévia dos resultados obtidos nos ensaios dilatométricos, algumas amostras dos aços $\mathrm{S}$ e $\mathrm{P}$, submetidas a taxas de resfriamento específicas, foram preparadas para análise microestrutural. 

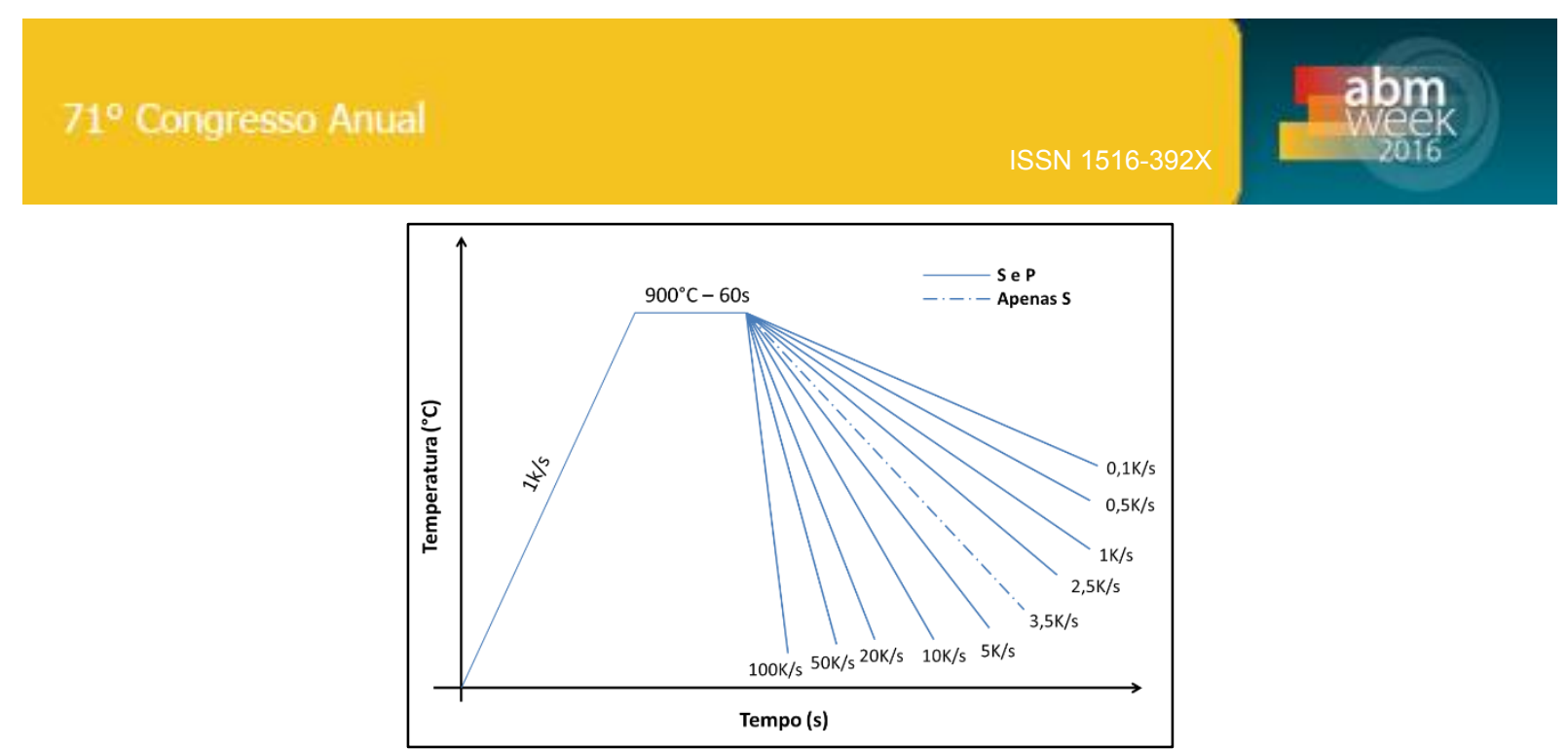

Figura 2. Ciclos térmicos propostos para ensaios de dilatometria com resfriamento contínuo, austenitização a $900^{\circ} \mathrm{C}$, taxa de aquecimento igual a $1 \mathrm{~K} / \mathrm{s}$.

\subsubsection{Caracterização Microestrutural}

Os aços foram caracterizados no estado de entrega e algumas amostras foram selecionadas após ensaios de dilatometria para auxiliar na interpretação dos resultados e confirmar os eventos observados nas curvas dilatométricas.

Amostras dos aços foram cortadas, embutidas, lixadas e polidas segundo os procedimentos usuais. Após o polimento, as amostras foram avaliadas em microscópio óptico Leica DM2700M do LTM-DEMET para análise de inclusões não metálicas. Realizou-se ataque químico para revelar a microestrutura e posterior análise em microscópio óptico e eletrônico de varredura (MEV), para o qual utilizouse o MEV TESCAN VEGA3 do Nanolab - REDEMAT.

\section{RESULTADOS E DISCUSSÃO}

\subsection{Caracterização Microestrutural do Estado de Entrega}

As Figuras 3 e 4 apresentam, respectivamente, as microestruturas das seções transversal e longitudinal dos boletos dos aços $\mathrm{S}$ e $\mathrm{P}$ no estado de entrega. Pode-se observar que ambos os aços são majoritariamente constituídos por perlita fina, o que é esperado em função de suas composições químicas e processamento termomecânico experimentado durante a fabricação. Destaca-se que não há diferenças significativas entre as seções longitudinal e transversal de cada aço, o que permite concluir a respeito da homogeneidade microestrutural destes materiais. No entanto, é possível observar uma significativa diferença entre as microestruturas dos aços S e P. Percebe-se, nas Figuras 3 e 4, que a microestrutura do aço P é mais refinada do que a do aço $S$, possuindo ela menor tamanho de colônias de perlita $(28 \mu \mathrm{m})$ e menor espaçamento interlamelar $(0,09 \mu \mathrm{m})$. No aço $\mathrm{S}$, o tamanho médio das colônias de perlita é $43 \mu \mathrm{m}$ e o espaçamento interlamelar $0,18 \mu \mathrm{m}$. Estes valores foram medidos com o auxílio de técnicas quantitativas aplicadas em um microscópio eletrônico de varredura e estão de acordo com o descrito na literatura para estes tipos de aço [6-8].

Destaca-se que os aços $\mathrm{S}$ e $\mathrm{P}$ estudados neste trabalho possuem pequena adição de $\mathrm{Cr}$, Mo e V sem significativa diferença entre eles, estando nos teores de C, Mn e $\mathrm{Si}$ as principais diferenças. Supõe-se que as diferenças nestes teores sejam suficientes para promover mudanças significativas na cinética da transformação austenita-perlita, o que terá consequências durante as etapas de reaquecimento, laminação e resfriamento dos trilhos. Segundo os fornecedores destes aços, o aço P 
experimentou taxas de resfriamento, após laminação, significativamente mais elevadas do que o aço $\mathrm{S}$. $\mathrm{O}$ aço $\mathrm{S}$ teria sido resfriado ao ar, enquanto o aço $\mathrm{P}$ submetido a um fluxo de água durante determinado tempo. Isto, associado à cinética de transformação de fase dos aços, que será melhor explorada a frente, poderia justificar as suas diferenças microestruturais no estado de entrega.
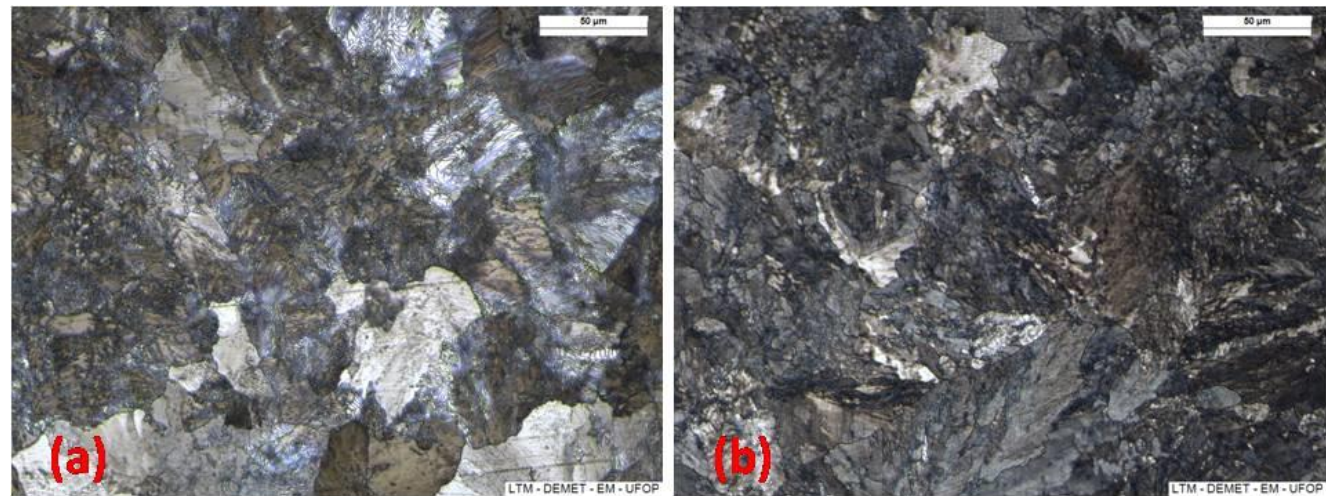

Figura 3. Microestruturas da seção transversal (a) do aço $S$ e (b) do aço P.

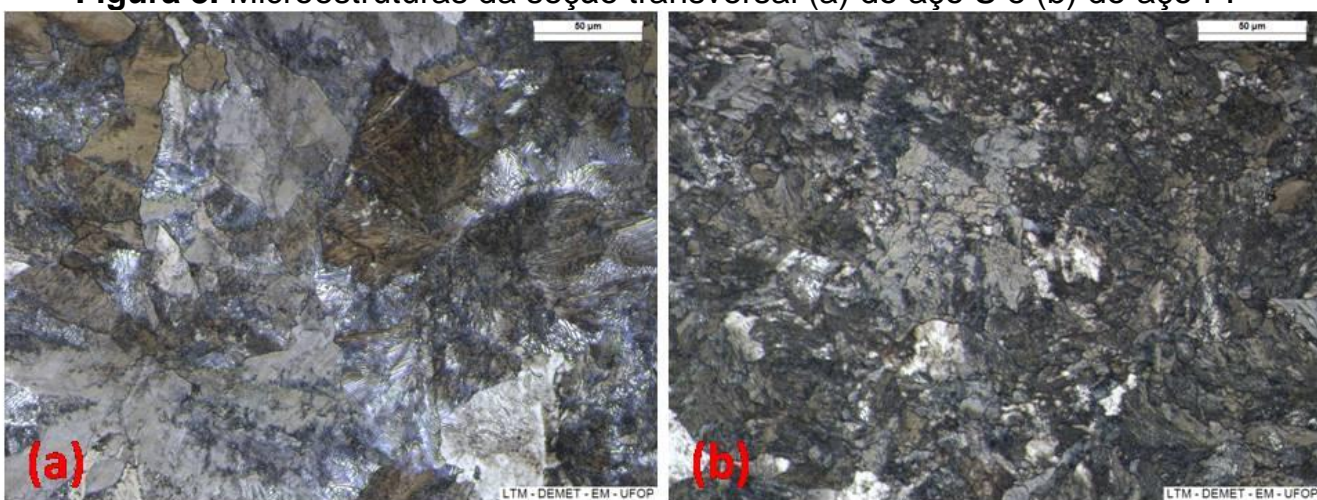

Figura 4. Microestruturas da seção longitudinal (a) do aço S e (b) do aço P.

As amostras dos aços $\mathrm{S}$ e $\mathrm{P}$ foram devidamente polidas e submetidas a análises de inclusões por meio da aplicação das técnicas de microscopia óptica e eletrônica de varredura-EDS. Pôde-se observar que ambos os aços, possuem os sulfetos de manganês como inclusões majoritárias. A Figura 5 apresenta imagens de MEV-EDS que identificam a concentração de manganês e enxofre nas inclusões. A Figura 6 apresenta as frações volumétricas de sulfeto de manganês nos aços estudados. Pode-se observar que as concentrações destas inclusões nos dois aços são semelhantes, visto os desvios experimentais de metalografia quantitativa. Os valores encontrados, entre $0,08 \%$ e $0,3 \%$ estão de acordo com o esperado para estes tipos de aço $[5,6]$. Segundo Olivares et al. (2011), os valores típicos de fração volumétrica de sulfeto de manganês em aços de aplicação ferroviária fabricados entre 2000 e 2005 variaram de $0,02 \%$ a $1,6 \%$. 

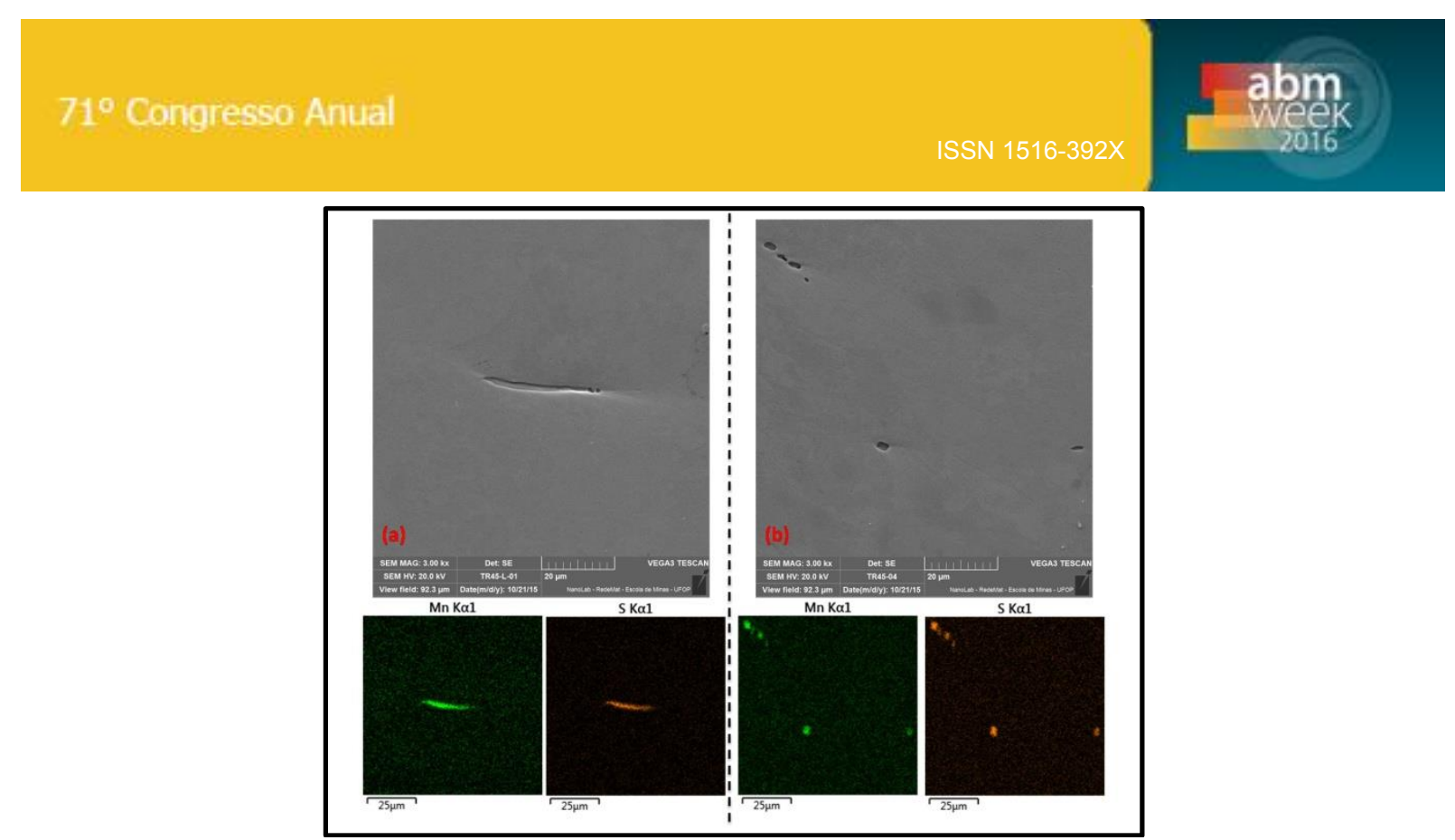

Figura 5. Caracterização química de inclusões no aço $S$ (a) na seção longitudinal e (b) na seção transversal - EDS-MEV.

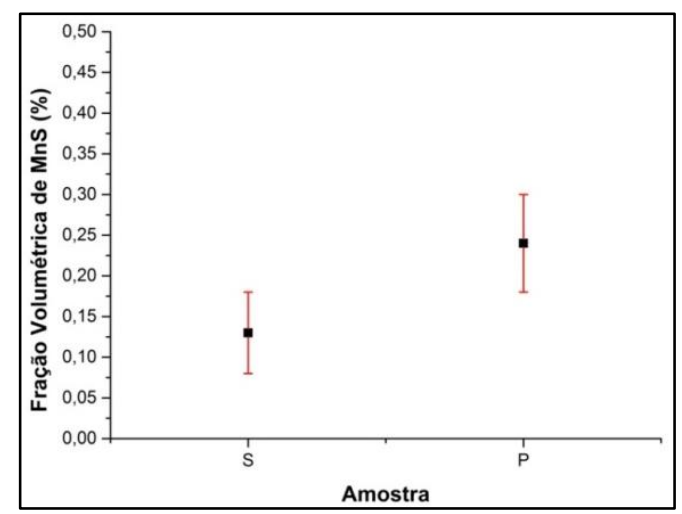

Figura 6. Comparativo entre as frações volumétricas de inclusões de sulfeto de manganês nos aços S e $P$.

\subsection{Ensaios de Dilatometria}

A Figura 7 apresenta as curvas dilatométricas de austenitização dos aços $\mathrm{S}$ e $\mathrm{P}$ quando aquecidos continuamente a uma taxa de $1 \mathrm{~K} / \mathrm{s}$. A Figura 8 apresenta um comparativo entre a cinética de austenitização dos aços $S$ e $P$ após tratamento matemático adequado. Pode-se observar que ambos os aços estudados obedecem uma lei cinética do tipo exponencial, como descrito pela Equação 1, onde $\mathrm{K}$ e $\mathrm{T}_{0}$ são constantes. A constante $\mathrm{K}$ é uma constante cinética que está relacionada à taxa média de transformação de fases e To é a temperatura, em Kelvin, onde a reação estudada tem início [13-16].

Neste contexto, é possível afirmar que a temperatura de início de austenitização dos aços S e P são, respectivamente, $707^{\circ} \mathrm{C}$ (980K) e $673^{\circ} \mathrm{C}$ (946K). Observa-se que, uma vez que a taxa de aquecimento foi constante, o tempo de nucleação da austenita no aço $\mathrm{P}$, assim como o tempo necessário para a austenitização completa, é significativamente menor do que no aço $S$.

Segundo Zhang et al. (2013), e outros pesquisadores, a austenitização destes aços depende fortemente de sua composição química e de sua microestrutura original. Segundo eles, quanto mais refinada for a microestrutura original, menor será o tempo para a etapa de nucleação da austenita, pois maior será a densidade de fronteiras de grão que serão pontos preferenciais para a nucleação heterogênea da 
nova fase. Associado a isto, Zhang et al. (2013) afirmam que, em aços alto carbono, a adição de $\mathrm{Mn}$ e $\mathrm{Cr}$ dificultam a dissolução da cementita, retardando a completa austenitização do aço. Neste contexto, pode-se dizer que os resultados obtidos estão coerentes, visto que o aço $\mathrm{P}$, além de possuir a estrutura inicial mais refinada, possui o menor teor de $\mathrm{Mn}$ em sua composição $[11,13]$.
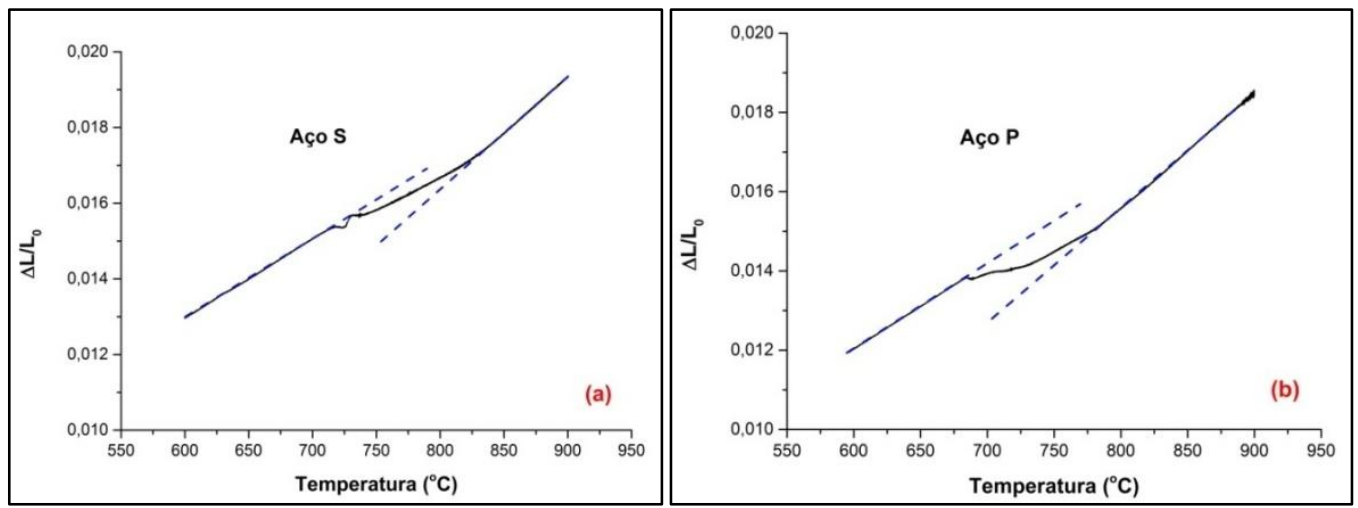

Figura 7. Curvas dilatométricas obtidas na austenitização dos aços (a) $\mathrm{S}$ e (b) $\mathrm{P}$ durante aquecimento a uma taxa de $1 \mathrm{~K} / \mathrm{s}$.

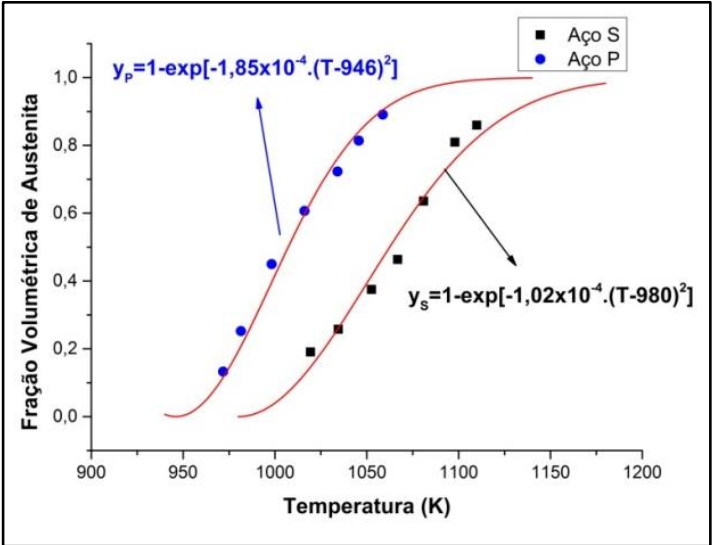

Figura 8. Comparativo entre as frações volumétricas de austenita formada durante aquecimento dos aços $\mathrm{S}$ e $\mathrm{P}$ a uma taxa de $1 \mathrm{~K} / \mathrm{s}$.

$$
y=1-\exp \left[-K .\left(T-T_{0}\right)^{2}\right]
$$

Vários corpos de prova dos aços $\mathrm{S}$ e $\mathrm{P}$ foram submetidos à mesma condição de austenitização e então resfriados com diferentes taxas, como já descrito no capítulo de Materiais e Métodos. As temperaturas críticas de início e final de transformação perlítica, assim como as temperaturas de início de transformação martensítica foram determinadas. A Figura 9 apresenta as curvas dilatométricas de resfriamento dos aços $S$ e $P$ quando submetidos a uma taxa de resfriamento de $5 \mathrm{~K} / \mathrm{s}$.

Pode-se observar que o aço $S$, apresenta uma expansão dilatométrica na faixa de temperatura entre, aproximadamente, $700^{\circ} \mathrm{C}$ e $500^{\circ} \mathrm{C}$ que é associada à formação de perlita à partir do aço austenitizado. Entretanto, nem toda austenita, nesta condição de resfriamento, teve condições cinéticas de se transformar em perlita, se transformando então em martensita. Uma segunda expansão nas proximidades de $200^{\circ} \mathrm{C}$ confirma a transformação martensítica.

$\mathrm{O}$ aço $\mathrm{P}$, para a taxa de resfriamento de $5 \mathrm{~K} / \mathrm{s}$, apresentou apenas a expansão associada à transformação austenita-perlita. Esta observação, permite concluir que a cinética de nucleação da perlita no aço $P$ é facilitada em relação ao aço $S$. Fato 
este que pode ser justificado, principalmente, por seu menor teor de manganês em relação ao aço $S$, uma vez que, nas mesmas condições de austenitização, o seu tamanho de grão austenítico prévio é semelhante ao do aço $S$ (ambos com valores médios de $45 \mu \mathrm{m})$, como apresenta a Figura 10.

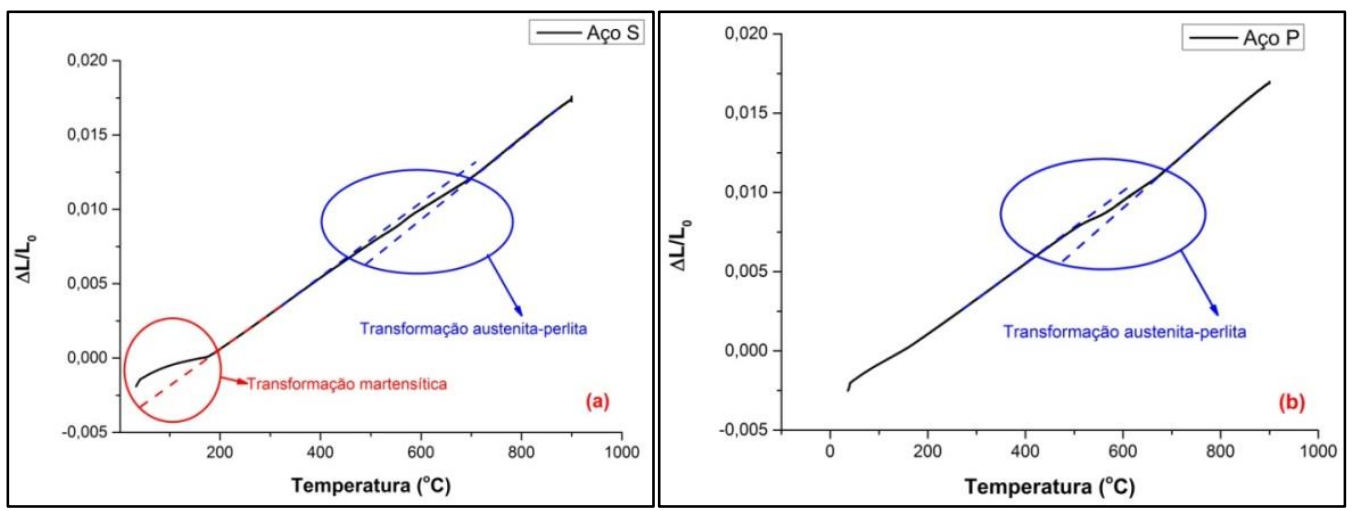

Figura 9. Comparativo entre as curvas dilatométricas de resfriamento dos aços (a) S e (b) Ppara uma taxa de resfriamento de $5 \mathrm{~K} / \mathrm{s}$.
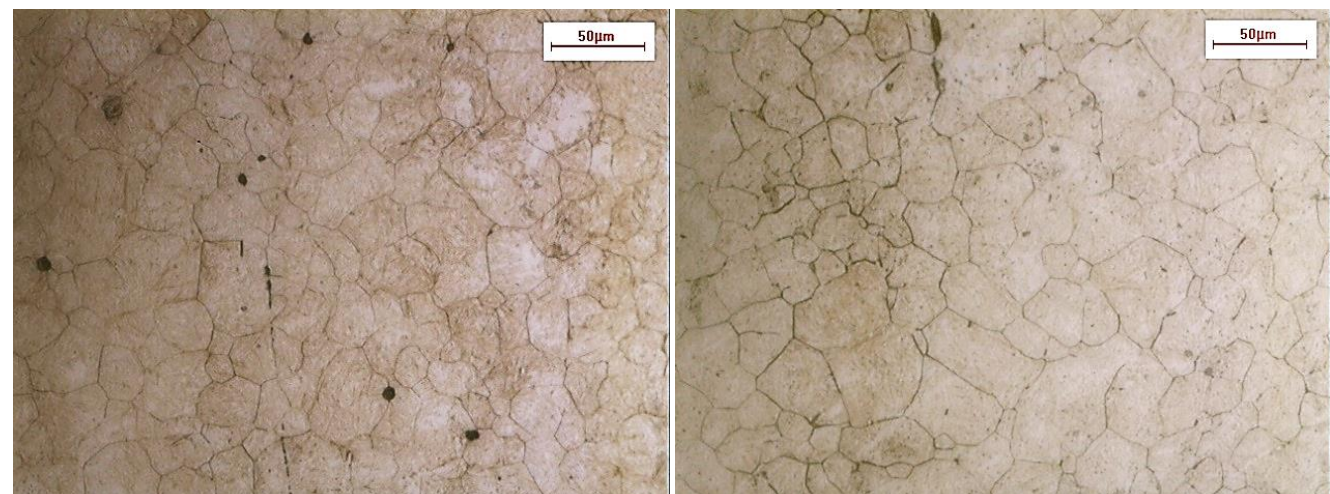

Figura 10. Grão austenítico prévio dos aços (a) $\mathrm{S}$ e (b) $\mathrm{P}$ austenitizados a $900^{\circ} \mathrm{C}$ por $60 \mathrm{~s}-\mathrm{MO}-$ Reativo de Éter $(50 \mathrm{~mL}$ de éter etílico, $80 \mathrm{~mL}$ de água destilada, $10 \mathrm{~mL}$ de detergente, 2 gotas de $\mathrm{HCl}$ e $3 g$ de ácido pícrico).

Por meio da análise das temperaturas críticas de transformação medidas nas curvas dilatométricas correspondentes às demais taxas de resfriamento $(0,1 ; 0,5 ; 1 ; 2,5$; 3,$5 ; 5 ; 10 ; 20 ; 50$ e 100K/s), foi possível propor os diagramas TRC dos aços S e P. A Figura 11 apresenta um comparativo entre os diagramas obtidos para os dois aços.

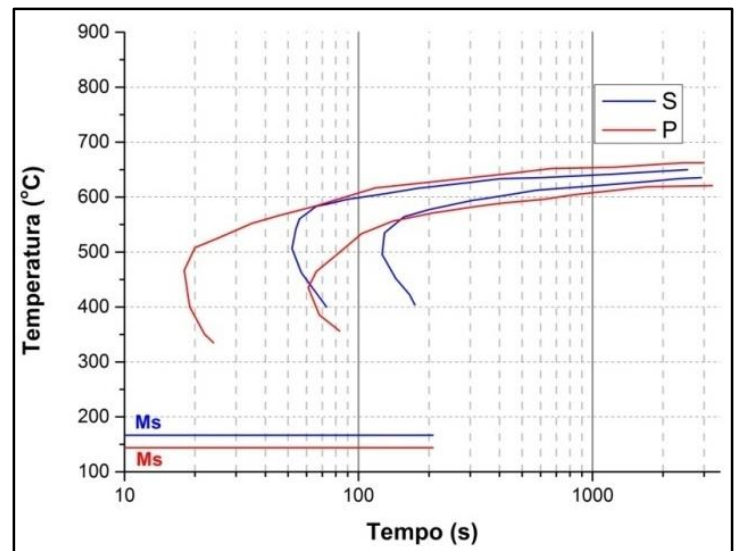

Figura 11. Comparativo dos diagramas TRC dos aços $\mathrm{S}$ e $\mathrm{P}$ determinados a partir dos aços austenitizados a $900^{\circ} \mathrm{C}$. 
Pode-se observar que ambas as curvas são clássicas curvas em "C", típicas de aços eutetóides, de forma que a curva do aço $\mathrm{P}(0,79 \%$ de $\mathrm{C}$ e $0,88 \%$ de $\mathrm{Mn})$ está deslocada para a esquerda em relação à do aço $S(0,72 \%$ de $C$ e $1,24 \%$ de $\mathrm{Mn})$. Isto indica que o tempo de nucleação dos constituintes difusionais é superior no aço $\mathrm{S}$.

Tendo em vista tamanhos de grão austeníticos prévios semelhantes, esta observação pode ser explicada principalmente em função da diferença de teores de Mn nos aços estudados. A maior concentração do Mn desloca a composição eutetóide para a esquerda e propicia maior estabilidade da austenita mesmo em temperaturas abaixo de Ac1. Assim sendo, a cinética de decomposição desta fase, no aço S, é retardada, justificando a sua curva mais deslocada para a direita [13-20]. Os elementos $\mathrm{Cr}$, Mo e $\mathrm{V}$ são fortes formadores de carbonetos que têm como efeito retardar a decomposição da austenita em constituintes difusionais na faixa de temperatura entre 500 e $400^{\circ} \mathrm{C}$. Quando estes elementos estão presentes em quantidades mais significativas, eles promovem nas curvas TRC uma separação dos campos de formação de perlita e bainita, desconfigurando o tradicional perfil em" $C$ " das curvas. Como os teores destes elementos nos aços estudados são baixos, não é de se esperar que este fenômeno ocorra, justificando assim, a configuração em "C" das duas curvas obtidas.

As temperaturas Ms determinadas para os aços $S$ e $P$ foram, respectivamente, $167^{\circ} \mathrm{C}$ e $150^{\circ} \mathrm{C}$. Estas temperaturas são relativamente baixas quando comparadas a aços estruturais hipoeutetóides, porém os valores são coerentes, pois a temperatura Ms é fortemente afetada pelo teor de $\mathrm{C}$ e de alguns outros elementos de liga. Em geral, o aumento no teor de $\mathrm{C}$ tende a diminuir a temperatura Ms.

\subsection{Caracterização Microestrutural dos Corpos de Prova de Dilatometria}

As Figuras de 12 a 14 apresentam as microestruturas dos corpos de dilatometria submetidos, respectivamente, às taxas de resfriamento de $0,1 \mathrm{~K} / \mathrm{s}, 5 \mathrm{~K} / \mathrm{s}$ e $20 \mathrm{~K} / \mathrm{s}$. Pode-se observar que para a menor taxa de resfriamento, a microestrutura dos dois aços é completamente perlítica e não se observa diferença tão significativa entre eles no que diz respeito ao tamanho das colônias de perlita e espaçamento interlamelar.

Esta observação é importante visto que confirma a hipótese do aço $P$ ter sua estrutura mais refinada no estado de entrega, não em função do refino de grão austenítico promovido pelos elementos formadores de carbonetos, como $\mathrm{Cr}$, V e Mo, mas sim em função da aplicação de um resfriamento mais rápido que promove um maior grau de superesfriamento, diminuindo o raio crítico de nucleação, aumentando assim a taxa de nucleação de perlita a uma temperatura mais baixa, onde não há energia suficiente para crescimento das lamelas de ferrita, gerando assim uma estrutura com menor tamanho médio de colônias de perlita e espaçamento interlamelar, como verificado no estado de entrega [13-20].

Deve-se destacar que o resfriamento acelerado do aço $P$, sem que ocorra a formação de martensita, fase indesejada neste aço, só é possível pelo fato do seu diagrama TRC estar mais deslocado para a esquerda. Caso a mesma lei de resfriamento fosse imposta ao aço $S$, durante o processo de fabricação, provavelmente ocorreria a transformação martensítica, em maior, ou menor extensão a depender da taxa de resfriamento imposta. Um importante resultado que confirma esta hipótese está apresentado na Figura 13, onde é possível observar as microestruturas dos aços $S$ e $P$ submetidas a uma taxa de resfriamento de $5 \mathrm{~K} / \mathrm{s}$. Observa-se que o aço $\mathrm{P}$ é constituído unicamente por perlita, com menor tamanho 
de colônia e menor espaçamento interlamelar do que o obtido a 1K/s (Figura 12-b). $\mathrm{O}$ aço $\mathrm{S}$, submetido à mesma condição de resfriamento apresentou significativa fração de martensita em sua estrutura (fase acicular com maior poder refletor na Figura 13-a) e perlita fina.

Para a taxa de resfriamento de $20 \mathrm{~K} / \mathrm{s}$, o aço $S$ já possui microestrutura completamente martensítica, enquanto o aço $\mathrm{P}$ continua apresentando perlita como constituinte majoritário. Perlita esta, ainda mais refinada, com menor tamanho de colônias e espaçamento interlamelar. Estrutura, inclusive, similar à do estado de entrega.
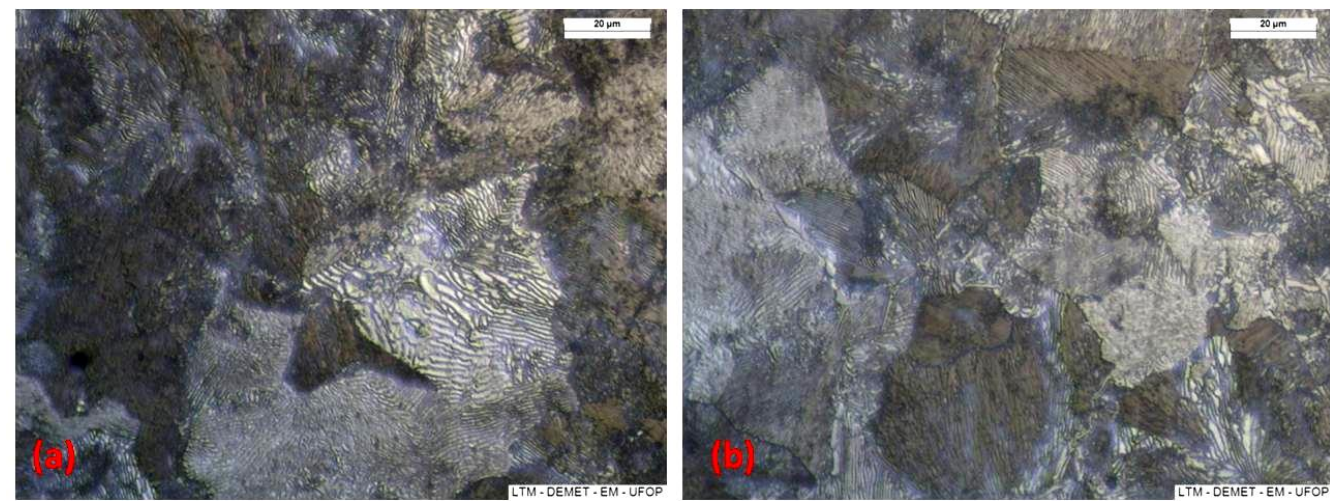

Figura 12. Microestruturas dos corpos de prova de dilatometriaaustenitizados a $900^{\circ} \mathrm{C}$ e resfriados a $0,1 \mathrm{~K} / \mathrm{s}$ (a) S, (b) P.
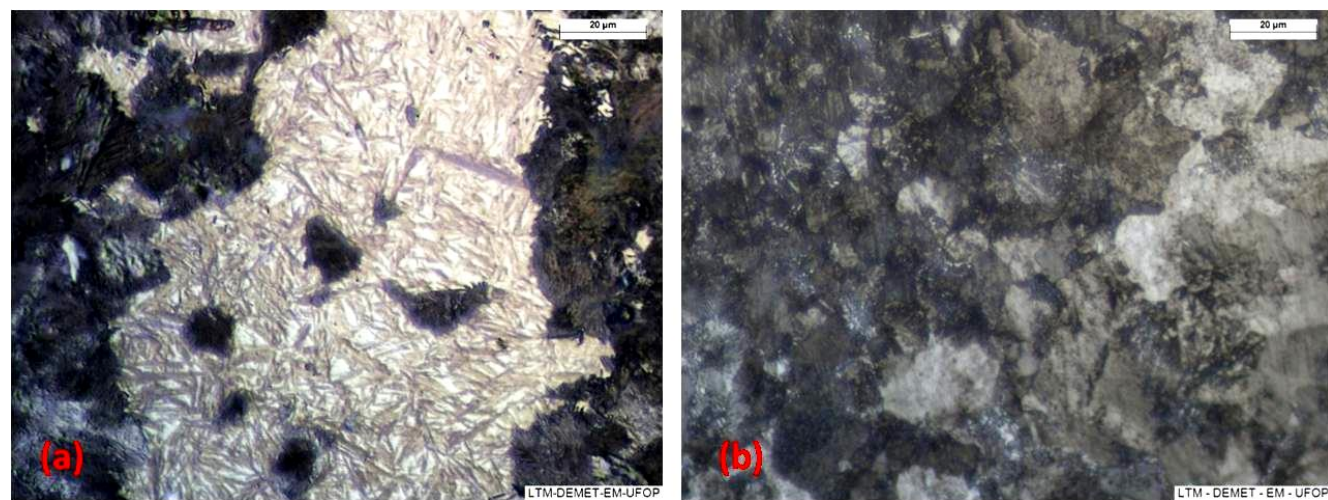

Figura 13. Microestruturas dos corpos de prova de dilatometriaaustenitizados a $900^{\circ} \mathrm{C}$ e resfriados a $5 \mathrm{~K} / \mathrm{s}$ (a) S, (b) P.
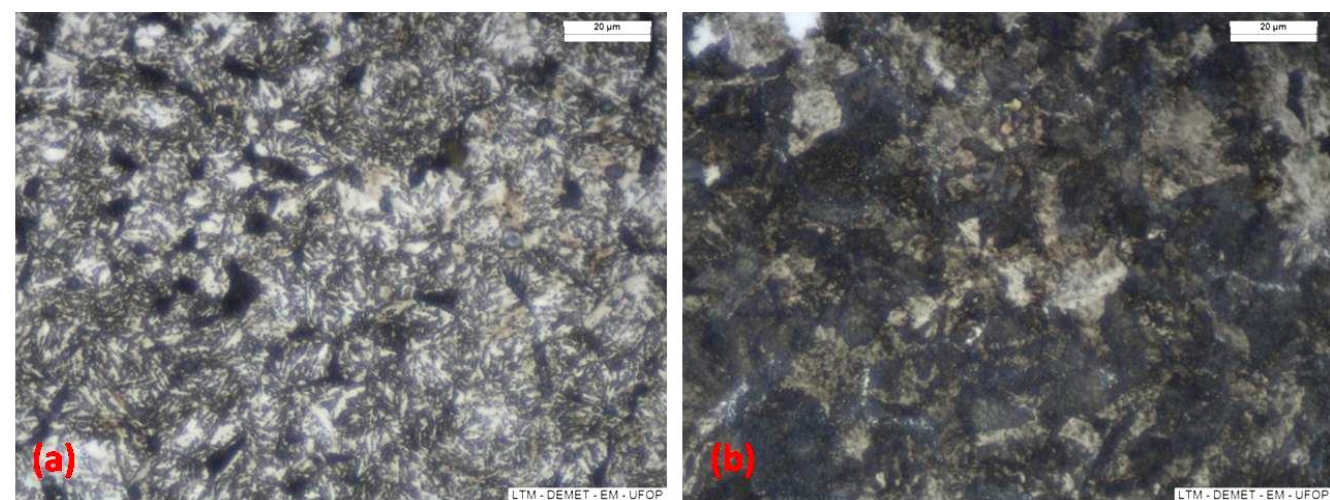

Figura 14. Microestruturas dos corpos de prova de dilatometriaaustenitizados a $900^{\circ} \mathrm{C}$ e resfriados a 20K/s (a) S, (b) P. 


\section{CONCLUSÃO}

Os aços $\mathrm{S}$ e $\mathrm{P}$, em seu estado de entrega, possuem microestruturas completamente perlíticas e homogêneas, não havendo diferenças significativas entre as seções longitudinal e transversal dos boletos;

$\mathrm{O}$ aço $\mathrm{P}$, em seu estado de entrega, apresentou microestrutura mais refinada do que o aço S. O seu tamanho médio de colônias de perlita e separação interlamelar são significativamente menores do que os verificados para o aço $\mathrm{S}$;

Em relação à natureza e nível de inclusões nos aços, pode-se concluir que as inclusões de sulfeto de manganês são as que se apresentam em maior significância, porém, mesmo assim, estão dentro dos limites esperados para este tipo de produto; Para a taxa de aquecimento de $1 \mathrm{~K} / \mathrm{s}$, as temperaturas de início de transformação austenítica para os aços S e P foram, respectivamente, $707^{\circ} \mathrm{C}$ e $673^{\circ} \mathrm{C}$. O tempo de nucleação da austenita foi menor no aço $P$ em função da existência do maior número de sítios para nucleação heterogênea. A cinética de austenitização contínua dos aços $S$ e $P$ obedecem a uma lei cinética exponencial adaptada do modelo de Johnson-Mehl-Avrami-Kolmogorov;

Durante resfriamento contínuo, a partir de uma microestrutura completamente austenítica a $900^{\circ} \mathrm{C}$, o tempo de nucleação da perlita no aço $\mathrm{P}$ é significativamente menor do que no aço $\mathrm{S}$, portanto as curvas de início de transformação do aço $\mathrm{P}$ são deslocadas para a esquerda em relação ao S. A menor concentração de Mn e Si no aço $P$ seria a principal causa deste comportamento, visto que os tamanhos de grão austenítico prévio são semelhantes;

As concentrações de $\mathrm{Cr}$, Mo e $\mathrm{V}$ encontradas nos aços estudados não são suficientes para que seja atribuída a elas a causa da microestrutura mais refinada do aço $P$ no estado de entrega. $O$ fato da curva de início de transformação perlítica do aço $\mathrm{P}$ ser mais deslocada para a esquerda e para baixo, em relação ao aço $\mathrm{S}$, permite que ele seja resfriado a taxas mais elevadas em seu processo de fabricação sem que haja transformação martensítica. Neste contexto, o elevado grau de superesfriamento é a principal causa do refino da estrutura no estado de entrega;

As temperaturas de início e final de transformação martensítica dos aços $\mathrm{S}$ e $\mathrm{P}$ foram em média, respectivamente, $167^{\circ} \mathrm{C}$ e $150^{\circ} \mathrm{C}$.

\section{Agradecimentos}

Os autores agradecem à VLI-FCA pela doação dos trilhos para a realização do presente estudo.

\section{REFERÊNCIAS}

1. Schneider, E. L. Análise da Vida Remanescente de Trilhos com Defeitos Transversais Desgastados em Serviço. Dissertação de Mestrado. Universidade Federal do Rio Grande do Sul, 2005.

2. Zerbst, U., Lindén, R., Edel, K. O., Smith, R. A. Introduction to the Damage Tolerance Behaviour of Railway Rails - A Review. Engineering Fracture Mechanics. 2009; 76:25632601.

3. Moreira, L. P.,Viana, T. G., Godefroid, L. B., Faria, G. L., Candido, L. C. Estudo da Tenacidade à Fratura de Cinco Aços Para Aplicação em Trilho Ferroviário. $70^{\circ}$ Congresso Anual da ABM - ABM Week. 2015. 
4. Godefroid, L. B., Faria, G. L., Cândido, L. C., Viana, T. G. Failure analysis of recurrent cases of fatigue fracture in flash butt welded rails. Engineering Failure Analysis. 2015; $55: 10.1016$.

5. AREMA - Manual for Railway Engineering. 2013; Vol. 1.

6. Olivares, R.O., Garcia, C. I., DeArdo, A., Kalay, S., Hernández, R. F. C., Advanced Metallurgical alloy design and thermomechanical processing for rails steels for North American heavy haul use. Wear. 2011; 273:364-373.

7. Hernandez, F. C. R., Kalay, S., Olivares, R. O., Garcia, C. I., DeArdo A. New rail steels for the 21st century. Railway Track Structures. 2008; 104:17-21.

8. Reiter, J., Bernhard, C., Presslinger, H. Austenite grain size in the continuous casting process: metallographic methods and evaluation. Materials Characterization. 2008; 59:737-746.

9. AGLAN, H.; HASSAN, M.; LIU, Z.; BHUYAN, M. Fracture Behavior of Bainitic and Pearlitic Rail Steel Webs. JournalofMaterials Science, v. 39, p. 4305 - 4307. 2004.

10. AGLAN, H.A.; FATEH, M. Fracture and Fatigue Crack Growth Analysis of Rail Steels. JournalofMechanicsofMaterialsandStructures,v. 2, p. 335 - 346. 2007.

11. Zhang, G., Chae, J., Kim, K., Suh, D. W. Effects of Mn, Si and Cr addition on the dissolution and coarsening of pearlitic cementite during intercriticalaustenitization in Fe1 mass\% alloy. Materials Characterization. 2013; 81:56-67.

12. Mansouri, H.,Monshi, A.,Hadavinia, H. Effect of Local Induction Heat Treatment on the Induced Residual Stresses in the Web Region of a Welded Rail. Journal of Strain Analysis for Engineering Design. 2004; 39:271-283.

13. Wang, L., Wang, Z., Lu, K. Grain size effects on the austenitization process in a nanostructured ferritic steel. ActaMaterialia. 2011;59:3710-3719.

14. Serajzadeh, S., Taheri, A. K. A study on austenite decomposition during continuous cooling of low carbon steel. Materials and Design. 2004. Vol. 25. pp. 673-679.

15. Agrawal, K., Brimacombe, J. K. Mathematical model of heat flow and austenite-pearlite transformation in eutectoide carbon steel rods for wire. Metallurgical Transactions B. 1981;12:121-133.

16. Verdi, C., Visintin, A. A Mathematical model of the austenite-pearlite transformation in plain carbon steel based on the scheil's additivity rule. Acta Met. 1987; 35:2711-2717.

17. Denis, S., Sjostrom, S., Simon, A. Coupled temperature, stress, phase transformation calculation model numerical illustration of the internal stress evolution during cooling of a eutectoid steel cylinder. Metallurgical Transactions A. 1987; 18:1203-1212.

18. Park, N., Khamsuk, S., Shibata, A., Tsuji, N. Effect of austenite grain size on kinetics of dynamic ferrite transformation in low carbon steel. ScriptaMaterialia. 2012. Vol. 60. pp. 611-614.

19. Pryds, N., Huang, $X$. The effect of cooling rate on the microstructure formed during solidification of ferritic steel. Metallurgical Transactions A. 2000. Vol. 31. pp. 3155-3166.

20. Zhao, J. C., Notis, M. R. Continuous cooling transformation kinetics versus isothermal transformation kinetics of steels: a phenomenological rationalization of experimental observations. Materials Science Engineering. 1995. Vol. 15. pp. 135-207. 